\title{
GHRONIQUE
}

\section{Eglantyne Jebb}

(Nécrologie)

Le 17 décembre s'est éteinte dans une clinique de Genève, après une longue et pénible maladie, la fondatrice de l'Union internationale de secours aux enfants, Eglantyne Jebb. Depuis la guerre on la voyait souvent dans cette ville qu'elle affectionnait en raison de la compréhension et de l'esprit international qu'elle y avait trouvés. Dès 1919, le Comité international de la Croix-Rouge avait accordé son patronage à l'œuvre britannique du Save the Children Fund, créé par elle, et, l'année suivante, se joignait à ce Fund et au Comité international de secours aux enfants fondé entre temps à Berne pour constituer l'Union internationale de secours aux enfants. Eglantyne Jebb avait la foi qui ne connaît pas d'impossibilités. Elle se rendit à Rome, et obtint du pape de lancer au monde catholique un appel en faveur des enfants des pays éprouvés. dans le même temps que l'archevêque de Cantorbéry et l'archevêque d'Upsal faisaient appel au monde protestant.

Eglantyne Jebb, hantée par l'idée des devoirs de l'humanité envers l'enfant, avait cherché à formuler ces devoirs dans quelques phrases brèves. De cette idée est sortie la déclaration des droits de l'enfant dite Déclaration de Genève. Qui a vu Eglantyne Jebb dans sa robe et ses voiles marrons, invraisemblablement mince, un lourd crucifix d'argent pendant sur sa poitrine, se levant dans une conférence, dans un congrès, à la Commission de la protection de l'enfance de la Société des Nations, trouvant en français, en anglais, les mots les plus incisifs pour plaider la cause de l'enfant, ne saurait l'oublier. Ses yeux bleus, au regard débordant de vie intérieure, avaient toujours une claire vision des êtres et des choses. Elle apparaissait comme la conscience de l'humanité.

Depuis deux ans, Eglantyne Jebb, transportée de clinique en clinique, ne suivait plus que de loin les pro- 


\section{CHRONIQUE}

\section{Les secours sur route.}

blèmes sociaux auxquels elle a voué sa vie. Pourtant, de temps à autre, elle envoyait un message qui jetait une vive lumière dans les assemblées auxquelles il était adressé. C'est ainsi que tout dernièrement la conférence d'études qui s'est tenue à Genève sur la question de l'enfance indigène et qui réunissait des personnalités marquantes des missions protestantes et catholiques et des représentants de la Société des Nations et du Bureau international $d u$ travail a pris pour base de ses travaux un mémoire dicté par l'inspiratrice de l'Union.

E. C.

\section{Les secours sur route en France ${ }^{1}$.}

L'attention du Comité international a été récemment attirée sur les secours que le Touring club de France a organisés sur un certain nombre de grandes routes françaises. Le Comité international a tout de suite écrit à la Croix-Rouge française pour lui demander quelle part elle prenait à cette œuvre, que la circulation de plus en plus intense et rapide rend si nécessaire; le Comité central de la Croix-Rouge française a répondu au Comité international, en date du 6 octobre, dans les termes suivants : ${ }^{2}$

" J'ai l'honneur de vous faire connaître que le Touring club a organisé, sur un certain nombre de grandes routes

1 Voy. dans La Revue du Touring club, 38me année, No 408, septembre 1928, p. 205 : "Les secours sur route"; p. 206 : "Le Touringclub français fait une démonstration du fonctionnement des postes de secours".

- La Revue internationale a publié dans son numéro de février 1927, p. 99, un important article du Brig.-general H.-B. Champain, C.M.G., secrétaire de la Croix-Rouge britannique : Le transport des malades et le secours d'urgence aux blessés. 